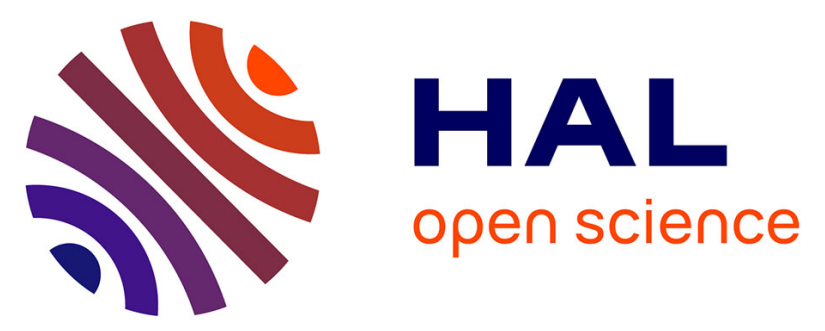

\title{
Influence of the hole population on the transient reflectivity signal of annealed low-temperature-grown GaAs
}

Valentin Ortiz, J. Nagle, Antigoni Alexandrou

\section{- To cite this version:}

Valentin Ortiz, J. Nagle, Antigoni Alexandrou. Influence of the hole population on the transient reflectivity signal of annealed low-temperature-grown GaAs. Applied Physics Letters, 2002, 80 (14), pp.2505. 10.1063/1.1463209 . hal-00836946

HAL Id: hal-00836946

https://hal-polytechnique.archives-ouvertes.fr/hal-00836946

Submitted on 19 May 2014

HAL is a multi-disciplinary open access archive for the deposit and dissemination of scientific research documents, whether they are published or not. The documents may come from teaching and research institutions in France or abroad, or from public or private research centers.
L'archive ouverte pluridisciplinaire HAL, est destinée au dépôt et à la diffusion de documents scientifiques de niveau recherche, publiés ou non, émanant des établissements d'enseignement et de recherche français ou étrangers, des laboratoires publics ou privés. 


\title{
Influence of the hole population on the transient reflectivity signal of annealed low-temperature-grown GaAs
}

\author{
V. Ortiz ${ }^{\mathrm{a})}$ and J. Nagle \\ Thales Research and Technology, Domaine de Corbeville, 91404 Orsay, France
}

\begin{abstract}
A. Alexandrou
Laboratoire d'Optique et Biosciences, CNRS UMR7645-INSERM U451-Ecole Polytechnique-ENSTA, 91128 Palaiseau, France
\end{abstract}

(Received 12 October 2001; accepted for publication 28 January 2002)

\begin{abstract}
We study the influence of the carrier dynamics on the transient reflectivity of low-temperature-grown GaAs samples. We report a precise modeling of the recorded reflectivity data, which exhibit multiexponential decays and changes in sign, using a standard point defect model and taking into account the effects of the band filling, band gap renormalization, and trap absorption. We show that the valence-band hole population plays an important role in the behavior of the signals, and that it must be taken into account in order to optimize low-temperature-grown GaAs-based devices. (C) 2002 American Institute of Physics. [DOI: 10.1063/1.1463209]
\end{abstract}

Low-temperature-grown GaAs (LT-GaAs) layers are extensively studied for ultrafast optoelectronic applications due to their improved subpicosecond carrier lifetime, high carrier mobility, and high breakdown fields. These interesting properties allow the realization of components such as $\mathrm{THz}$ sources and detectors, saturable semiconductor absorber mirrors, or ultrafast metal-semiconductor-metal photodetectors. ${ }^{1}$ The properties of the LT-GaAs depend both on the growth conditions (growth temperature, growth rate, V/III ratio, etc.) during the molecular-beam epitaxy (MBE) process, and on the postgrowth annealing (duration and temperature).

It is known that during the growth step, excess As is incorporated, which leads to the formation of a high density $\left(10^{17}-10^{20} \mathrm{~cm}^{-3}\right)$ of $\mathrm{As}_{\mathrm{Ga}}$-related point defects. ${ }^{2}$ These defects form a midgap band, and act as nonradiative recombination centers that decrease the carrier lifetimes. When the growth temperature is lowered, more defects are incorporated, and thus the carrier lifetime is reduced. ${ }^{3}$ During the postgrowth annealing step, the carrier lifetime is generally increased due to the precipitation of the point defects in As clusters, although the annealed layers can also show an unexpectedly reduced carrier lifetime in some specific cases. ${ }^{4}$

One of the most effective ways to characterize the LTGaAs material without the need to process devices is to perform transient reflectivity measurements. The signal decay is then usually roughly interpreted as the decay of the excess carrier lifetime in the material, ${ }^{3}$ and the optimization of the growth/annealing conditions performed in view of the desired final application. However, some unexplained behaviors such as negative or slow transients are observed in asgrown or very lightly annealed samples, in reflectivity but also in transmittance experiments. ${ }^{5,6}$ They usually disappear when the material is annealed at temperatures higher than $600^{\circ} \mathrm{C}$. This behavior was attributed to a change in the defect-to-band absorption when the injected excess carriers

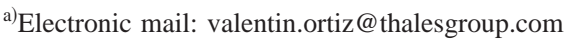

are trapped in the defect levels. ${ }^{6}$ Thus, the induced absorption should be only observable in samples with a high defect concentration, i.e., the as-grown samples. However, in the reflectivity measurements that we present here, although there are no negative transients in as-grown and $500{ }^{\circ} \mathrm{C} / 60 \mathrm{~s}$ annealed LT-GaAs samples, we observe them in the same samples after an anneal of $500{ }^{\circ} \mathrm{C} / 10 \mathrm{~min}$. These experimental facts show the need for a more accurate physical description of the transient.

In this letter, we report results on the modeling of transient differential reflectivity $(\Delta R)$ measurements of LTGaAs samples. We used a standard point defect model, which takes into account the electron and hole populations, and calculated the effects of band filling, band gap shrinkage, and trap absorption. We found that most of the previously unexplained behaviors are due to the influence of a slowly varying hole population in the valence band.

The two samples studied here were realized by MBE on a Varian Mod Gen II reactor. They consist of a $2 \mu \mathrm{m}$-thick LT-GaAs layer embedded between 20 nm-thick $\mathrm{Al}_{0.25} \mathrm{Ga}_{0.75} \mathrm{As}$ layers in order to avoid surface recombination and leakage of the photogenerated carriers to the substrate. Growth rates of $1 \mu \mathrm{m} / \mathrm{h}$ and a V/III ratio of 3.0 were used. ${ }^{7}$ The deep donor (DD) concentrations deduced by high resolution $\mathrm{x}$-ray diffraction $(\mathrm{HRXRD})^{8}$ are $N^{0}{ }_{\mathrm{DD}} \sim 5.9$ $\times 10^{19} \mathrm{~cm}^{-3}\left(0.31 \%\right.$ excess As, sample A), $1.5 \times 10^{19} \mathrm{~cm}^{-3}$ $(0.08 \%$ excess As, sample B). The samples were then ex situ flash annealed for $500^{\circ} \mathrm{C}$ and $700^{\circ} \mathrm{C}$ during $60 \mathrm{~s}$, and for $500^{\circ} \mathrm{C}$ during $10 \mathrm{~min}$. As expected, we observed a reduction of the DD concentration with increased annealing temperature. For the $\Delta R$ measurements, we used pump and probe beams from a Ti:Sapphire oscillator with wavelengths of 812 $\mathrm{nm}$ and $100 \mathrm{fs}$ full width half maximum pulse duration. The pump beam of $70 \mathrm{~mW}$, focused down to $50 \mu \mathrm{m}$, is expected to generate about $7 \times 10^{17} \mathrm{~cm}^{-3}$ electron-hole pairs in the probed region.

Figures 1 and 2 show the measured $\Delta R$ signals. During the pump pulse duration, the signal rapidly increases to a maximum value, then it rapidly decreases in the following 


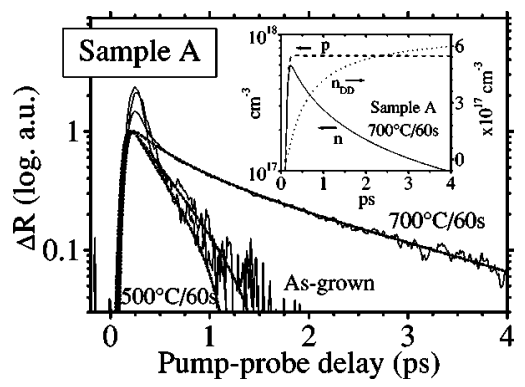

FIG. 1. Transient reflectivity signals (log. scale) for the sample A as-grown and annealed $60 \mathrm{~s}$ for $500{ }^{\circ} \mathrm{C}$ and $700{ }^{\circ} \mathrm{C}$ (solid lines) and their respective modeling (dotted lines) with $N_{\mathrm{DD}}=5.9 \times 10^{19} / N_{A}=1.5 \times 10^{18} \mathrm{~cm}^{-3}, N_{\mathrm{DD}}$ $=1.5 \times 10^{19} / N_{A}=1.6 \times 10^{18} \mathrm{~cm}^{-3}$ and $N_{\mathrm{DD}}=8.9 \times 10^{17} / N_{A}=8.9 \times 10^{17}$ $\mathrm{cm}^{-3}$. Inset: calculated transient CB-electron, VB-holes, and nonionized donor concentrations for sample A annealed $700{ }^{\circ} \mathrm{C} / 60 \mathrm{~s}$.

$0.2 \mathrm{ps}$. This is attributed to the relaxation and the cooling of carriers to the bottom of the bands. Then, for sample A asgrown and annealed at $500^{\circ} \mathrm{C}$ and $700{ }^{\circ} \mathrm{C}$ for $60 \mathrm{~s}$ (Fig. 1), a nonexponential decrease of the signal is observed, which corresponds to the carrier trapping by the DD states. For the samples annealed $500{ }^{\circ} \mathrm{C}$ during $10 \mathrm{~min}$ (Fig. 2), we observe, after a fast subpicosecond decrease, an important negative reflectivity signal with a slow return to the equilibrium. This behavior is not observed in our as-grown samples.

To explain these different behaviors, we developed a Shockley-Read-Hall model including thermal processes 4 which allows the calculation of the transient electron and hole populations. The Fermi level is fixed by the compensation between the amount of incorporated acceptors $\left(N_{A}\right)$ and the incorporated donors $\left(N_{\mathrm{DD}}\right)$. The acceptor concentration, in the absence of doping, is most likely constituted by either the Ga vacancy defects generated during the LT-GaAs deposition and annealing ${ }^{9}$ or by the residual doping during the MBE growth. The rate equations concern the electrons $n$ in the conduction band (CB), the holes $p$ in the valence band (VB) and the nonionized deep donors $n_{\mathrm{DD}}$ in the defect band. For example, the decay rate of electrons $n$ from the $\mathrm{CB}$ to the DD states reads $-\beta_{\mathrm{CB} \rightarrow \mathrm{DD}} n\left(N_{\mathrm{DD}}-n_{\mathrm{DD}}\right)$, where $\beta_{\mathrm{CB} \rightarrow \mathrm{DD}}$ is the CB-electron capture coefficient by the ionized DD centers (proportional to the carrier thermal velocity and the electron capture cross section $\sigma_{e}$ ). We also took into account the effect of the absorption by the nonionized DD, with an additional generation term in the $\mathrm{CB}$-electron population $\alpha_{\mathrm{DD}} I / h \nu$, where $I$ is the incident pump power, $h v$ the pho-

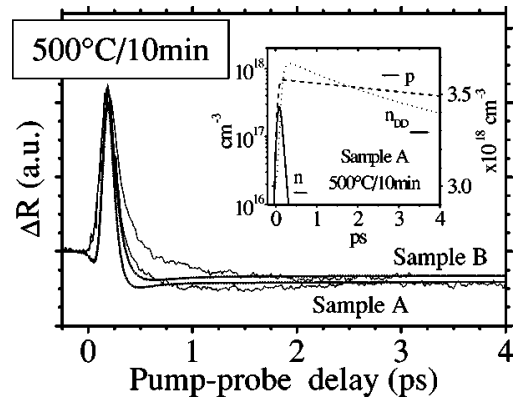

FIG. 2. Transient reflectivity signals for the samples A and B annealed 10 min for $500{ }^{\circ} \mathrm{C}$ (solid lines) and their respective modeling (dotted lines) with $N_{\mathrm{DD}}=1.9 \times 10^{19} / N_{A}=7 \times 10^{18} \mathrm{~cm}^{-3}$ and $N_{\mathrm{DD}}=7.5 \times 10^{18} / N_{A}=6$ $\times 10^{18} \mathrm{~cm}^{-3}$. Inset: calculated transient $\mathrm{CP}$-electron, VB-holes, and nonionized donor concentrations for the sample A. ton energy and $\alpha_{\mathrm{DD}}=\sigma_{\mathrm{DD}} n_{\mathrm{DD}}$ the DD absorption. Here $\sigma_{\mathrm{DD}}$ is the DD absorption cross section. We neglected Auger and band-to-band recombination since these effects are much slower than the nonradiative recombination in our present case.

After calculating the values of the carrier concentrations, we deduced the variation of the refractive index. For this, we calculated the variation of the absorption coefficient due to different effects: band-gap renormalization (BGR), ${ }^{10}$ band filling $(\mathrm{BF}){ }^{10}$ and DD absorption. Following the data presented in Ref. 10, we neglected the free carrier absorption. For the BGR, we used a law of the type $\Delta E_{g}=\alpha\left(n^{1 / 3} / m_{e}\right.$ $\left.+p^{1 / 3} / m_{d h}\right)$, where $m_{d h}=\left(m_{l h}^{3 / 2}+m_{h h}^{3 / 2}\right)^{2 / 3}$ and $\alpha$ is a proportionality constant determined to fit experimental results. Using the Kramers-Kronig relation, we then deduce the refractive index variation $\Delta n$, and thus $\Delta R$ (which was found to be proportional to $\Delta n$, as expected). We did not attempt to model the initial fast thermalization and cooling process.

The method adopted to fit the experimental results is the following: we fixed the DD absorption cross section to $\sigma_{\mathrm{DD}}$ $=2 \times 10^{16} \mathrm{~cm}^{2}$, which gives $\alpha_{\mathrm{DD}}=5 \times 10^{3} \mathrm{~cm}^{-1}$ for $\mathrm{N}_{\mathrm{DD}}$ $=2.5 \times 10^{19} \mathrm{~cm}^{-3}$ according to the experimental results in Ref. 11, and chose a unique best set of CB-electron and VB-hole cross sections $\left(\sigma_{n}\right.$ and $\left.\sigma_{p}\right)$ for all samples: $\sigma_{n}=$ $6 \times 10^{-15} \mathrm{~cm}^{2}$ and $\sigma_{p}=1 \times 10^{-17} \mathrm{~cm}^{2}$, values in agreement with those reported in previous studies, ${ }^{12}$ The $\mathrm{N}_{\mathrm{DD}}$ for each sample is given by the value measured by HRXRD and we end up with one single fitting parameter for each experiment: $N_{A}$. By changing this value, we must be able to describe every observed behavior.

In Figs. 1 and 2 are plotted the calculated results for the samples studied (dotted lines). Concerning the $60 \mathrm{~s}$-annealed sample (Fig. 1), we obtain an accurate description of the $\Delta R$, which reproduces the nonexponential decays and the lifetime reduction after an annealing at $500^{\circ} \mathrm{C} / 60 \mathrm{~s}$. The range of the values found for $N_{A}$ are in agreement with other values reported in the literature. ${ }^{13}$

For the long-annealed samples (Fig. 2), we obtain a good fit and a good description of the observed negative transient. The discrepancy between the model and the experimental data for very short times $(<1 \mathrm{ps})$ is attributed to the thermalization process, which is not taken into account. The high $N_{A}$ we have here $\left(\sim 6-7 \times 10^{18} \mathrm{~cm}^{-3}\right)$ ensures a high amount of ionized DD, and therefore many more empty states for electrons in the DD band than for holes. This leads to an extremely fast decrease of the CB-electron density compared to the VB-hole one (see inset of Fig. 2), which gives an initial subpicosecond decay time (associated with the decay of $\mathrm{CB}$ electrons) and then a slow negative signal with the same decay rate as that of the VB holes. The negative contribution of VB holes to $\Delta n$ (at $\lambda \sim 812 \mathrm{~nm}$ ) is calculated in Fig. 3, where the different contributions to $\Delta R$ are described in the case of the sample $\mathrm{A}$ annealed $500{ }^{\circ} \mathrm{C} / 10 \mathrm{~min}$. These calculations also show that the DD absorption contribution is negligible compared to the $\mathrm{BF}$ and BGR one.

In Fig. 4, we show the calculated $\Delta n$ as a function of the excitation wavelength for the sample A annealed $700^{\circ} \mathrm{C} / 60 \mathrm{~s}$ and $500^{\circ} \mathrm{C} / 10 \mathrm{~min}, 1.5 \mathrm{ps}$ aiter the carrier injection, and the 


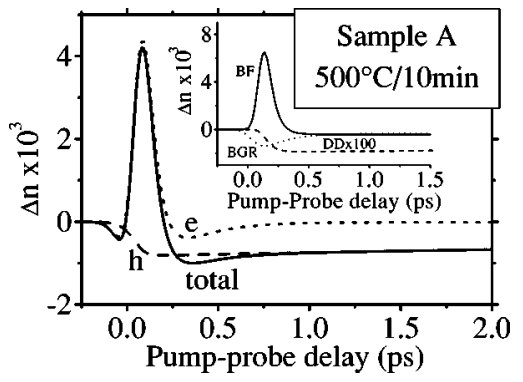

FIG. 3. Calculated real part of the refractive index variation (proportional to $\Delta R$ ) for the sample A annealed $500{ }^{\circ} \mathrm{C} / 10 \mathrm{~min}$. Calculations for a pumpprobe wavelength at $\lambda=812 \mathrm{~nm}$, taking into account only the hole population (the electron one is arbitrarily set to zero, dashed line), and only the electron population (dotted line); solid line: complete calculation. Inset: contributions of the BGR (dotted line), the BF (solid line) and the DD absorption (dashed line, $\times 100$ ) to the $\Delta n$.

$\Delta n$ related to $\mathrm{CB}$ electrons and to $\mathrm{VB}$ holes. We can see that the negative VB-hole contribution dominates for the sample A annealed $500{ }^{\circ} \mathrm{C} / 10 \mathrm{~min}$, while in the case of the $700^{\circ} \mathrm{C} / 60 \mathrm{~s}$ annealing, the signal remains positive at $812 \mathrm{~nm}$ due to the strong contribution of the remaining CB electrons. We should mention here that the negative contribution of VB holes is in fact related to their higher effective mass, which gives a different shape of the $\Delta n$ versus $\lambda$ curve and thus a negative $\Delta R$ at $812 \mathrm{~nm}$. Besides, this dependence of wavelength can be employed to probe selectively for example the electron population (with a pump-probe wavelength of about $780 \mathrm{~nm}$ ).

It is interesting to note that the high amount of $N_{A}$, which leads to the predicted negative transients, can be either due to a generation of Ga vacancies during our long annealing cycles but also to an important residual doping in the MBE reactor. ${ }^{14}$ Besides, we should note that an alternative way to have an important $N_{A}$ is to grow $p$-doped LT-GaAs: in fact, the photoreflectance studies performed at $800 \mathrm{~nm}$ in

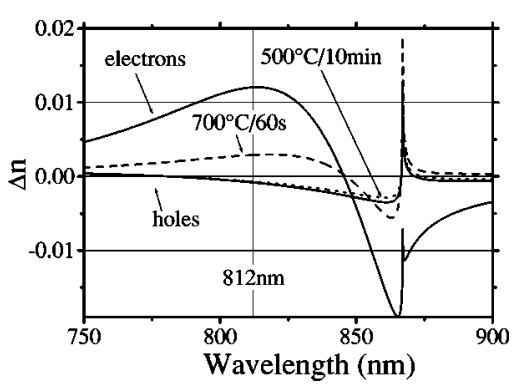

FIG. 4. Calculated $\Delta n$ for electrons (we set $n=7 \times 10^{17} \mathrm{~cm}^{-3}$ and $p=0$ ) and holes (we set $n=0$ and $p=7 \times 10^{17} \mathrm{~cm}^{-3}$ ), as a function of the probe wavelength (solid lines). Dashed and dotted lines: calculated $\Delta n$ for the sample A annealed $700{ }^{\circ} \mathrm{C} / 60 \mathrm{~s}$ and $500{ }^{\circ} \mathrm{C} / 10 \mathrm{~min}, 1.5 \mathrm{ps}$ after the pulse injection, respectively. The calculation takes into account the effects of the $\mathrm{BF}, \mathrm{BGR}$, and DD absorption. such types of layers ${ }^{15}$ show the same negative transients as ours.

In summary, we performed $\Delta R$ measurements on LTGaAs layers, which exhibit nonexponential behaviors as well as negative reflectivity signals. These are described accurately by a general point-defect model that uses the DD concentration (measured by HRXRD) and the net acceptor concentration in the LT-GaAs layer as input parameters. This model allows the calculation of the transient carrier populations in the material and the modeling of the associated $\Delta R$. We showed that the negative signals of the samples with long annealing times can be explained by a slowly decreasing hole population. This is related to a high amount of acceptors present in the matrix.

The authors thank R. Bisaro for HRXRD measurements, and X. Marcadet and J.F. Lampin for useful discussions. Part of this work has been performed in the frame of European EUCLID project "HELIOS," supported by the French MOD under DGA/DSP/STTC Contract No. 98390.

${ }^{1}$ D. D. Nolte, J. Appl. Phys. 85, 6259 (1999), and references therein.

${ }^{2}$ D. C. Look, Z.-Q. Fang, J. R. Sizelove, and C. E. Stutz, Phys. Rev. Lett. 70, 465 (1993).

${ }^{3}$ K. A. McIntosh, K. B. Nichols, S. Verghese, and E. R. Brown, Appl. Phys. Lett. 70, 354 (1997)

${ }^{4}$ M. Stellmacher, J. Nagle, J.-F. Lampin, P. Santoro, J. Vaneecloo, and A. Alexandrou, J. Appl. Phys. 88, 6026 (2000).

${ }^{5}$ S. Gupta, G. Mourou, F. W. Smith, and A. R. Calawa, Mater. Res. Soc. Symp. Proc. 241, 205 (1991).

${ }^{6}$ U. Seigner, R. Fluck, G. Zhang, and U. Keller, Appl. Phys. Lett. 69, 2566 (1996).

${ }^{7}$ J. C. Bourgoin, H. Hammadi, M. Stellmacher, J. Nagle, B. Grandidier, D. Stievenard, J. P. Nys, C. Delerue, and M. Lannoo, Physica B 273, 725 (1999); M. Stellmacher, Ph.D. thesis, Ecole Polytechnique, 1999.

${ }^{8}$ G. M. Martin, Appl. Phys. Lett. 39, 747 (1981); X. Liu, A. Prassad, W. M. Chen, A. Kurpiewski, A. Stoschek, Z. Liliental-Weber, and E. R. Weber, ibid. 65, 3002 (1994).

${ }^{9}$ M. Luysberg, H. Sihn, A. Prasad, P. Specht, Z. Lillental-Weber, and E. R. Weber, J. Appl. Phys. 83, 561 (1998).

${ }^{10}$ B. R. Bennett, R. A. Soref, and J. A. del Alamo, IEEE J. Quantum Electron. QE-26, 113 (1990).

${ }^{11}$ D. Strab, M. Ruff, S. U. Dankowski, P. Kiesel, M. Kneiss1, S. Malzer, U. D. Keil, and G. H. Dohler, J. Vac. Sci. Technol. B 14, 2275 (1996).

${ }^{12}$ M. Stellmacher, J. P. Schnell, D. Adam, and J. Nagle, Appl. Phys. Lett. 74, 1239 (1999); A. J. Lochtefeld, M. R. Melloch, J. C. P. Chang, and E. S. Harmon, ibid. 69, 1465 (1996).

${ }^{13}$ M. H. Chan, S. K. So, K. T. Chan, and G. G. Kellert, Appl. Phys. Lett. 67, 834 (1995); The uncertainty for the extracted values of $N_{A}$ is relatively low once the capture cross sections are fixed, which implies that the $N_{A}$ uncertainty is directly related to the uncertainty of the capture cross sections.

${ }^{14}$ This implies that two materials grown on two different reactors at exactly the same temperature, growth rate, and V/III ratio and with the same amount of incorporated excess As can have different transient behaviors due to the different amount of incorporated acceptors.

${ }^{15}$ W. K. Liu, D. I. Lubyshev, P. Specht, R. Zhao, E. R. Weber, J. Gebauer, A. J. SpringThorpe, R. W. Streater, S. Vijarnwannaluk, W. Songprakob, and R. Zallen, J. Vac. Sci. Technol. B 18, 1594 (2000). 